\title{
Description of Review of Literature between Social Science and Applied Science by Scholars
}

\author{
R. Venkatesh Aravindh ${ }^{\# 1}$, S. Thirupathi ${ }^{* 2}$ \\ ${ }^{1,2}$ Doctoral Research Scholar, Department of Journalism and Mass Communication, \\ Periyar University, Salem, Tamil Nadu, India
}

\begin{abstract}
Review of literature is an integral part of a research process. It gives researcher lots of inputs and information from a variety of perspectives, angles and viewpoints on the area of research that the researcher is working on apart from the adjacent areas concerning the same. The review of literature also helps the researcher to gain a new direction for the research and also in even formulating the research problem. Apart from the aforementioned aspects, the review of literature also gives a broader and deeper understanding to the researcher to look at the areas and aspects of research that were done by various scholars cutting across geographies around the world. The aspect of describing and writing the review of literature varies in a multitude of forms and dimensions across various streams. There are also differences especially with respect to the subjects concerning the research stream. This research paper is envisioned to establish the differences between the description of review of literature in social sciences and applied sciences.
\end{abstract}

Keywords - Description; Review; Literature; Social Sciences; Applied Sciences

\section{Introduction}

According to A. Fink (2005) a literature review looks at the books, scholarly articles, and other sources relevant to a particular issue. It also includes other areas of research and theory by providing a description or summary and sometimes a critical evaluation of these works in relation to the research problem at large. He also added that literature reviews are designed to provide an overview of sources explored while researching a particular topic.

\section{Review of Literature}

A summary is a recap of the important information from the source (Hart C., 2018). The key features of a literature review are:

- Giving a new interpretation of older contents and combine new interpretations.

- Tracing the changes in the field.

- Evaluating the sources and choosing the most relevant research.

The purpose of a literature review is to:

- To understand the research problem being studied by various researchers.

- Describing others works under consideration.

- Identify new ways to interpret research in the same field of study.

- Reveal any gaps that exist in the literatures of published work.

- Identifying conflicts among contradictory studies done previously.

- Discuss the need for additional research. (Jesson et., al 2011) (Ridley D., 2012).

\section{Methodology}

The current research study looks at the description of review of literature in review of literature in social sciences and applied sciences by comparing reviews from both the streams of research.

\section{Analysis and Findings}

Sara Gancho (2017) quoted Bern of and Li (2008) who affirmed that it is highly important to understand how relationships come about in social media. These research studies spoke about the earlier aspects of relationships being perceived by users in social media. This proves the notion of social science research which relies on previous studies to look for directions and a possible solution or a newer dimension to the already existing problem.

The above research studies were quoted by $\mathrm{Md}$. Mamun-ur-Rashid, Md. Golam Rabbani Akanda in 2015 to look in to improving the livelihood of fishermen families in Bangladesh. Their main objective was to tap ICT to improve the livelihood of fishermen families in Bangladesh. This proves the basic notion of an applied research in looking to provide soutions to underlying practical problems in the society.

\section{Conclusion}

The current research study was envisioned to look into how the review of literature is being seen in the streams of social sciences and applied sciences. The research study looked into reviews relating to both the streams of research by analysing previously done research and giving real

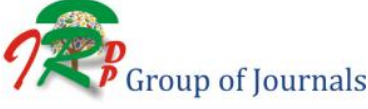


examples to compare the streams and meet the aforementioned objective of the research study. It is concluded that the streams have their own distinctive approaches and ways of looking at past studies to report on the larger issue taken up for their respective research areas.

\section{References}

[1] Bern off, J., \& Li, C. (2008). Harnessing the power of the oh-sosocial web. MIT Sloan management review, 49(3), 36.

[2] Fink, A. (2005). Conducting research literature reviews: From the internet to paper. Sage.

[3] Hart,C.(2018). Doing a Literature Review: Releasing the Research Imagination. Sage.

[4] Jesson, J., Matheson, L., \& Lacey, F. M. (2011). Doing your literature review: Traditionaland systematic techniques. Sage.

[5] Ridley,D. (2012). The literature review: A step-by-step guide for students. Sage.

[6] Retreived from http://libguides.usc.edu/ writingguide /literaturereview.

[7] Retreived from http://www.fisheriesjournal.com/ vol2issue4 /Pdf/2-4-17.11.pdf

[8] Sara Gancho (2017). (PDF) Social Media: a literature review. Available from: https://www.researchgate.net /publication/319660384_Social_Media_a_literature_review [accessed Jul 15 2018].

[9] Mamun-ur-Rashid, M., \& Akanda, M. G. R. (2015). Fish farmer's access to information communication media:A gender based comparative study in a selected village of Bangladesh. 